\title{
BMJ Open Mortality outcomes for Chinese and Japanese immigrants in the USA and countries of origin (Hong Kong, Japan): a comparative analysis using national mortality records from 2003 to 2011
}

\author{
Katherine G Hastings, ${ }^{1}$ Karen Eggleston, ${ }^{2}$ Derek Boothroyd, ${ }^{3}$ \\ Kristopher I Kapphahn, ${ }^{3}$ Mark R Cullen, ${ }^{4}$ Michele Barry, ${ }^{5}$ Latha P Palaniappan ${ }^{1}$
}

To cite: Hastings KG, Eggleston K, Boothroyd D, et al. Mortality outcomes for Chinese and Japanese immigrants in the USA and countries of origin (Hong Kong, Japan): a comparative analysis using national mortality records from 2003 to 2011. BMJ Open 2016;6: e012201. doi:10.1136/ bmjopen-2016-012201

- Prepublication history and additional material is available. To view please visit the journal (http://dx.doi.org/ 10.1136/bmjopen-2016012201).

Received 9 April 2016 Revised 27 September 2016 Accepted 30 September 2016

CrossMark

For numbered affiliations see end of article.

Correspondence to Dr Latha P Palaniappan; lathap@stanford.edu

\section{ABSTRACT}

Background: With immigration and minority populations rapidly growing in the USA, it is critical to assess how these populations fare after immigration, and in subsequent generations. Our aim is to compare death rates and cause of death across foreign-born, US-born and country of origin Chinese and Japanese populations.

Methods: We analysed all-cause and cause-specific age-standardised mortality rates and trends using 2003-2011 US death record data for Chinese and Japanese decedents aged 25 or older by nativity status and sex, and used the WHO Mortality Database for Hong Kong and Japan decedents in the same years. Characteristics such as age at death, absolute number of deaths by cause and educational attainment were also reported.

Results: We examined a total of 10458849 deaths. All-cause mortality was highest in Hong Kong and Japan, intermediate for foreign-born, and lowest for US-born decedents. Improved mortality outcomes and higher educational attainment among foreign-born were observed compared with developed Asia counterparts.

Lower rates in US-born decedents were due to decreased cancer and communicable disease mortality rates in the US heart disease mortality was either similar or slightly higher among Chinese-Americans and Japanese-Americans compared with those in developed Asia counterparts.

Conclusions: Mortality advantages in the USA were largely due to improvements in cancer and communicable disease mortality outcomes. Mortality advantages and higher educational attainments for foreign-born populations compared with developed Asia counterparts may suggest selective migration. Findings add to our limited understanding of the racial and environmental contributions to immigrant health disparities.

\section{INTRODUCTION}

Epidemiological transitions are well underway in developing countries, and patterns of

\section{Strengths and limitations of this study}

- First study to examine national mortality by disaggregated Asian subgroups and nativity status, in comparison to rates in country of origin using over a decade of data. Lack of country of origin comparisons in previous studies has limited our full understanding of how populations fare after immigration to the USA.

- US mortality death records may contain errors in the documented cause of death and racial/ethnic misclassification leading to under-represented or over-represented cause-specific death rates.

- Foreign-born data do not indicate duration of residence, and does not differentiate between naturalised immigrants, permanent residents, non-immigrants (eg, temporary workers, students and visitors) and illegal immigrants.

- Incomplete country comparison groups for the Chinese population (Hong Kong) as available in the WHO Mortality Database may limit our interpretations. However, this segmented Chinese population better controls for differences in level of economic development and access to medical technologies, etc.

disease are beginning to reflect those seen in developed countries. Non-communicable diseases such as cardiovascular disease (CVD) and cancers are now the leading causes of death around the world, accounting for $68 \%$ (38 million) of all deaths globally in 2012, an increase from $60 \%$ (30 million) in $2000 .{ }^{1}$ While widely studied in native populations, our understanding of disease patterns in diverse and immigrant populations is limited. Worldwide, immigration rates are increasing at unprecedented rates, with global immigrant population projections estimated to double in size to 405 million by $2050,{ }^{2}$ yet little research explores how nativity status (foreign-born vs native-born) may play a role 
in health or mortality risk factors. Prior evidence has documented serious health disparities between immigrant populations and host populations, with many immigrants experiencing significantly worse health outcomes and disproportionately suffering from heart attacks, cancer, diabetes, strokes and HIV/AIDS compared with native populations. ${ }^{3}$

Host and sending countries differ, as do the selfselection of immigrants; poor immigrants fleeing violence and poverty differ from professionals migrating for education and career opportunities. Given the lack of data quantifying immigrant health in national databases (ie, lack of acculturation proxies, undocumented immigrants, language barriers during data collection, unrepresentative, etc), studies find inconsistent conclusions regarding health risks in host countries. For example, some studies describe lower CVD risks and mortality among recent immigrants to developed countries compared with long-term immigrants; ${ }^{4-6}$ others describe increased risks. ${ }^{7-9}$ The 'Healthy Migrant Effect $^{10}$ posits that on many measures, new immigrants are healthier than average for the sending country, and may also be healthier than subsequent generations who share similar ethnic or racial backgrounds in the host country. This selective migration reflects both that migrants are often of higher socioeconomic status (SES) than the average population of the sending country (despite lower socioeconomic positions within the host country), as well as of better health conditional on SES. ${ }^{11}$

However, even healthy immigrants from developing countries have been exposed to a different disease environment in childhood than those born in developed countries, and may be more prone to communicable diseases and infection-induced cancers. These conflicting factors suggest that immigrants may have worse or better health than host populations in the USA or other highincome countries, in addition to facing other known risk factors of immigration such as restricted healthcare access, language barriers, lower relative SES, discrimination and more. Additionally, data are severely lacking among specific racial/ethnic immigrant groups, such as Asian subgroups.

Asian populations constitute over $60 \%$ of the world's population (4.4 out of 7.3 billion people). ${ }^{12}$ Asians are the fastest growing racial/ethnic group in the USA and are projected to double in size to over 34 million by $2060 .{ }^{13}$ Recent data disaggregated by individual subgroups have raised awareness about morbidity and mortality risks that impact certain Asian-Americans disproportionately, ${ }^{14-17}$ but none have explored these differences by nativity status in comparison to sending country. Our study focuses on two specific AsianAmerican subgroups, Chinese and Japanese. Census data from 2011 show that Chinese-Americans are nearly five times greater than the Japanese-American population (3 520150 vs 756898 , respectively). ${ }^{18}$ Differences in immigration histories, as described in separate study, ${ }^{19}$ have resulted in almost twice as many Chinese immigrants than Japanese immigrants in recent decades ( $70 \%$ vs $39 \%$, respectively) with settlements in different regions throughout the USA. Subgroups are also genetically, culturally and behaviorally diverse, which may affect mortality risks.

The purpose of this study is to (1) examine decedent characteristics and cause of death differences by nativity (foreign-born vs US-born) for Chinese-Americans and Japanese-Americans to capture heterogeneity between two commonly aggregated racial/ethnic groups, (2) to compare outcomes to country of origin to observe how mortality burden shifts on immigration to the USA and (3) to report mortality trends from 2003 to 2011. To the best of our knowledge, this is the first study of its kind. These comparisons will add to our understanding of the racial and environmental contributions to immigrant health disparities in support of improved research agendas, clinical guidelines and health policies.

\section{METHODS}

\section{US study population}

We examined US national mortality records from the National Center for Health Statistics' (NCHS) Multiple Cause of Death files from years 2003 to 2011. Decedents represent non-Hispanic Chinese and Japanese populations as identified on the death records by a funeral director using national guidelines. All analyses are confined to individuals aged 25 years or older to account for potential data limitations in accounting for competing risks (ie, maternal/infant mortality) in crosscountry comparisons. All 50 states and DC were included in the analysis, thus results are generalisable.

Year of death, age, sex, location of death, nativity status (foreign-born and US-born), race/ethnicity of the decedent and the underlying cause of death (disease or injury that initiated the events resulting in death) were identified from death certificates. Note that the foreign-born variable only indicates 'born outside of the USA', and does not provide country of birth details. 'Underlying cause of death' was coded by NCHS using the International Classification of Diseases, 10th revision (ICD-10). Year by year population estimates were calculated from the 2000 and 2010 US Census data using linear interpolation for 2003-2009 and extrapolation for 2011. To evaluate the appropriateness of the linear interpolation approach, we used American Community Survey (ACS) data to plot total US population by year in each group of interest and none of these plots appeared to show a consistent departure from linearity. Additionally, to calculate population estimates by nativity status, we used the Public Use Microdata Sample (PUMS) from the 5-year 2005-2009 ACS database to determine proportions of foreign-born populations for each Asian subgroup, age group, and sex by state and aggregated those numbers to the nation. For ACS, use of 5 -year data is required to provide complete coverage, and the 2005-2009 data are the earliest available and also 
cover the middle 5 years out of 9 included. However, analyses of individual years will be affected by changes in the percentages of foreign-born and US-born. We adjusted the estimates of per cent foreign-born using a linear adjustment based on the overall change in foreign-born from the 2000 and 2010 US Censuses.

\section{Chinese and Japanese counterparts in developed Asia}

To compare Asian-American mortality to that of ethnic counterparts living in developed Asia, we examined decedent-level mortality records from Hong Kong and Japan from the WHO Mortality Database from 2003 to 2011 which can be obtained from their website (http:// www.who.int/healthinfo/mortality_data/en/). Although Chinese-Americans may come from a range of regions (People's Republic of China, Hong Kong, Macao, Taiwan, southeast Asia), we selected Hong Kong as representative of ethnic Chinese living in developed Asia because of Hong Kong's high-quality cause-specific mortality data and similarities in potential conditions shaping health outcomes (affluence, urbanisation, healthcare, etc). Since Hong Kong has among the best survival rates of all China's cities/provinces, ${ }^{20}$ this comparison helps to isolate the differences associated with lifetime exposure to an earlier phase of the epidemiological transition among Chinese living in Asia, rather than current living standards. Whole country data for Japan were available and used for comparison to Japanese-American decedents. Average annual population estimates by age and sex from the WHO database were used to calculate age-standardised mortality rates.

\section{Statistical analysis}

The following causes of death (ICD-10 codes) were chosen as outcome variables: all cause, all cancer (C00-C97), heart disease (I00-I09, I13, I20-I51), cerebrovascular disease (I60-I69), communicable diseases, maternal, and nutritional conditions (A00-B99, G00-G04, N70-N73, J00-J06, J10-J18, J20-J22, H65-H66, O00-O99, P00-P96, E00-E02, E50, D50-D53, D64.9, E51-E64), Influenza and pneumonia (J09-J18), Alzheimer's disease (G30), accidents (V01-X59, Y85-Y86), and chronic lower respiratory diseases (J40-J47). The classification scheme used to categorise all 358 causes of deaths was selected to encompass the leading causes of death in the USA and developed Asia, including the primary noncommunicable diseases as well as an aggregated communicable disease category. ${ }^{21}$ For males and females in each group of interest, we first calculated raw mortality rates in each age group and then directly standardised these rates with the 2000 WHO Standard Population to calculate age-standardised mortality rates. We then present these results stratified by sex (female and males). ${ }^{22}$

\section{RESULTS}

We examined a total of 10458849 (352 822 in Hong Kong, 9959489 in Japan and 146538 in the USA) deaths from 2003 to 2011. One of our first objectives was to observe decedent characteristics between US Chinese and Japanese populations, compared with developed Asia counterparts, as shown in table 1. In general, females constituted about half of each subgroup, with the exception of foreign-born Japanese ( $78 \%$ females). The median age of death was also similar across Chinese subgroups, around 80 years old, whereas Japanese had a 7 -year difference in median age of death between US-born and foreign-born decedents (84 vs 77 years old, respectively). Females had higher median ages of death compared with man across all groups. Among both Chinese and Japanese, foreign-born decedents have received more education than the adult populations in developed Asia, as measured by rates of high school completion, and US-born decedents attained either similar (among Japanese) or higher rates of high school completion (table 1). Among Chinese-Americans, 'less than secondary (high school) completed' was $21 \%$ for US-born vs $41 \%$ for foreign-born, and 'secondary completed' was $52 \%$ for US-born vs $35 \%$ for foreign-born. Educational attainment was similar for Japanese-Americans, regardless of nativity; but over $60 \%$ of Japanese-American decedents had completed high school, compared with only $38 \%$ of the Japan population.

Consistent with 2010 Census population data, ${ }^{23}$ a much larger proportion of Chinese-American decedents was foreign-born, whereas for Japanese-American decedents, a larger proportion was US-born. According to the absolute number of deaths due to a specific cause (table 1), cancer ranked as the top cause of death for foreign-born and developed Asia decedents in each of the subgroups (when females and males are aggregated), but heart disease ranked as the leading cause for all US-born counterparts. Cerebrovascular disease ranked third for the US-born and foreign-born Asian-American subgroups, but ranked fourth (with communicable diseases ranking as third) for countries of origin.

Next, we sought to observe differences in cause of death for Chinese-Americans and Japanese-Americans, and compare rates to developed Asia counterparts as shown in table 2 and figure 1 . All-cause mortality rates were highest in Hong Kong (434 per 100000 for females, 783 for males) and Japan (408 for females, 799 for males), intermediate for foreign-born Chinese (319 for females, 468 for males) and Japanese-Americans (429 for females, 614 for males), and lowest for US-born Chinese (260 for females, 383 for males) and Japanese (345 for females, 600 for males; table 2). Overall death rates are lower in US-born decedents compared with countries of origin, and this is largely due to the difference in cancer deaths in the USA for Chinese and Japanese compared with developed Asia counterparts. Heart disease rates were either similar or slightly higher among Chinese and Japanese in the USA compared with those in Asia, with a higher mortality burden from heart disease for US-born decedents. Mortality rates for communicable diseases were much higher in Asia. The 
Table 1 Decedent characteristics using death record data for Chinese and Japanese populations in the USA and in developed Asia counterparts (Hong Kong and Japan), 2003-2011

\begin{tabular}{|c|c|c|c|c|c|c|}
\hline \multirow[b]{2}{*}{ Characteristics } & \multicolumn{3}{|c|}{ Chinese } & \multicolumn{3}{|c|}{ Japanese } \\
\hline & Hong Kong & Foreign born & US born & Japan & Foreign-born & US born \\
\hline Female (\%) & 44 & 48 & 46 & 46 & 78 & 47 \\
\hline \multicolumn{7}{|l|}{ Age at death ( $\mathrm{n}(\%$ of total)) } \\
\hline $25-44$ & $14344(4.1)$ & $2843(3.6)$ & $579(5.6)$ & $244460(2.5)$ & $445(3.0)$ & $600(1.4)$ \\
\hline $45-64$ & $58852(16.7)$ & $12211(15.7)$ & $1716(16.7)$ & $1341391(13.5)$ & $2118(14.5)$ & $4174(9.6)$ \\
\hline $65-74$ & $65330(18.5)$ & 12324 (15.8) & $1197(11.6)$ & $1772960(17.8)$ & 3437 (23.5) & $4373(10.0)$ \\
\hline $75-84$ & 115505 (32.7) & 23306 (29.9) & $3064(28.8)$ & 3118854 (31.3) & $6114(41.8)$ & $13941(31.9)$ \\
\hline $85+$ & $98791(28.0)$ & 27274 (35.0) & 3740 (36.3) & 3481824 (35.0) & 2517 (17.2) & $20565(47.1)$ \\
\hline Median age of deaths & 78 & 80 & 81 & 80 & 77 & 84 \\
\hline Female/male & $82 / 75$ & $82 / 78$ & $83 / 79$ & $84 / 77$ & $77 / 71$ & $85 / 82$ \\
\hline Total number of deaths & 352822 & 77958 & 10296 & 9959489 & 14631 & 43653 \\
\hline Average population size & 5087389 & 1805385 & 316337 & 95717355 & 260884 & 371188 \\
\hline \multicolumn{7}{|l|}{ Absolute numbers of deaths due to } \\
\hline Cancer & 111090 & 24841 & 2657 & 3012577 & 4913 & 9837 \\
\hline Heart disease & 54964 & 18019 & 2806 & 1631231 & 2791 & 11284 \\
\hline Cerebrovascular diseases & 30958 & 6569 & 805 & 1144770 & 1103 & 3726 \\
\hline $\begin{array}{l}\text { Communicable, maternal and } \\
\text { nutritional conditions }\end{array}$ & 54162 & 5373 & 571 & 1245295 & 813 & 2565 \\
\hline Influenza and pneumonia & 43910 & 3427 & 343 & 990576 & 357 & 1697 \\
\hline Alzheimer's disease & 102 & 1473 & 242 & 25988 & 430 & 1545 \\
\hline Accidents & 6612 & 2517 & 392 & 363844 & 567 & 1277 \\
\hline Chronic lower respiratory diseases & 18541 & 2866 & 238 & 172038 & 468 & 1226 \\
\hline \multicolumn{7}{|l|}{ Education attainment } \\
\hline Less than secondary completed & $52.4^{*}$ & 41.0 & 21.0 & $42.9^{\star}$ & 17.0 & 21.0 \\
\hline Secondary (high school) completed & $29.0^{*}$ & 35.0 & 52.0 & $37.9^{\star}$ & 66.0 & 63.0 \\
\hline Tertiary (college) completed & $18.6^{*}$ & 24.0 & 27.0 & $19.2^{*}$ & 17.0 & 16.0 \\
\hline
\end{tabular}

*International education attainment (ie, Hong Kong and Japan) was obtained from Barro-lee Educational Attainment data set, based on the population in 2005 (approximate mid-year) for individuals aged 25+; data can be retrieved at: http://barrolee.com/; individual-level educational data not available within WHO mortality records. 
Table 2 Age-adjusted mortality rates with $95 \%$ Cls by top causes of death for Chinese and Japanese populations in the USA and living in Asia (2003-2011). Data based on individuals aged 25+years

\begin{tabular}{|c|c|c|c|}
\hline \multirow[b]{2}{*}{ Cause of death } & \multirow[b]{2}{*}{$\begin{array}{l}\text { Asia } \\
\text { Rate }(95 \% \mathrm{Cl})\end{array}$} & \multicolumn{2}{|c|}{ U.S } \\
\hline & & $\begin{array}{l}\text { Foreign-born } \\
\text { Rate }(95 \% \mathrm{Cl})\end{array}$ & $\begin{array}{l}\text { US.-born } \\
\text { Rate (95\% Cl) }\end{array}$ \\
\hline \multicolumn{4}{|l|}{ Female } \\
\hline Chinese & Hong Kong & & \\
\hline All cause & 434.4 (432.1 to 436.7$)$ & 319.0 (315.7 to 322.3 ) & 260.3 (252.2 to 268.6 ) \\
\hline Cancer & 143.9 (142.5 to 145.3$)$ & $107.2(105.2$ to 109.2$)$ & 84.1 (79.1 to 89.3$)$ \\
\hline Heart disease & $68.5(67.6$ to 69.4$)$ & $69.4(67.9$ to 70.9$)$ & 57.2 (53.6 to 60.9$)$ \\
\hline Cerebrovascular diseases & 41.1 (40.4 to 41.8$)$ & 29.9 (28.9 to 30.9$)$ & 21.1 (18.9 to 23.5$)$ \\
\hline $\begin{array}{l}\text { Communicable, maternal and nutritional } \\
\text { conditions }\end{array}$ & $58.2(57.4$ to 58.9$)$ & 19.8 (19.0 to 20.6$)$ & 13.3 (11.6 to 15.2$)$ \\
\hline Influenza and pneumonia & 46.1 (45.5 to 46.8$)$ & $12.1(11.5$ to 12.7$)$ & 7.7 (6.5 to 9.2$)$ \\
\hline Alzheimer's disease & $0.1(0.1$ to 0.2$)$ & $6.9(6.5$ to 7.4$)$ & $6.1(5.2$ to 7.4$)$ \\
\hline Accidents & $6.5(6.2$ to 6.8$)$ & $10.2(9.6$ to 10.9$)$ & 9.1 (7.6 to 10.8$)$ \\
\hline Chronic lower respiratory diseases & $12.8(12.5$ to 13.2$)$ & $7.2(6.7$ to 7.7$)$ & $5.1(4.0$ to 6.4$)$ \\
\hline Japanese & Japan & & \\
\hline All cause & 408.4 (408.0 to 408.9 ) & 429.0 (420.6 to 437.7$)$ & 344.9 (338.4 to 351.6$)$ \\
\hline Cancer & 134.7 (134.4 to 135.0$)$ & 150.8 (145.7 to 156.2$)$ & $103.9(100.0$ to 108.0$)$ \\
\hline Heart disease & 64.5 (64.3 to 64.7$)$ & 75.9 (72.5 to 79 to 5$)$ & 69.5 (67.0 to 72.3$)$ \\
\hline Cerebrovascular diseases & 46.7 (46.5 to 46.8$)$ & 33.3 (30.9 to 35.8$)$ & 30.2 (28.4 to 32.2$)$ \\
\hline $\begin{array}{l}\text { Communicable, maternal and nutritional } \\
\text { conditions }\end{array}$ & 41.7 (41.6 to 41.9$)$ & 23.4 (21.5 to 25.5$)$ & 18.5 (17.1 to 20.2$)$ \\
\hline Influenza and pneumonia & 30.4 (30.3 to 30.5$)$ & $9.7(8.5$ to 11.1$)$ & 9.9 (8.9 to 11.0$)$ \\
\hline Alzheimer's disease & $1.1(1.1$ to 0.1 .1$)$ & $13.8(12.4$ to 15.4$)$ & 9.7 (9.0 to 10.6$)$ \\
\hline Accidents & $15.4(15.3$ to 15.5$)$ & $15.8(14.1$ to 17.8$)$ & 10.6 (9.2 to 12.2$)$ \\
\hline \multirow{2}{*}{\multicolumn{4}{|c|}{ Male }} \\
\hline & & & \\
\hline Chinese & Hong Kong & & \\
\hline All cause & 783.0 (779.5 to 786.5$)$ & 468.1 (463.5 to 472.6$)$ & 383.2 (372.6 to 394.0$)$ \\
\hline Cancer & 269.7 (267.6 to 271.7 ) & 160.6 (157.9 to 163.3$)$ & 102.1 (96.6 to 108.0$)$ \\
\hline Heart disease & 111.0 (109.7 to 112.3$)$ & $103.9(101.7$ to 106.0$)$ & $112.8(107.1$ to 118.8$)$ \\
\hline Cerebrovascular diseases & $60.2(59.2$ to 61.1$)$ & 34.1 (32.9 to 35.4$)$ & 26.0 (23.4 to 29.0$)$ \\
\hline Communicable and nutritional conditions & $113.4(112.1$ to 114.6$)$ & 32.5 (32.0 to 33.7 ) & 20.5 (18.2 to 23.1$)$ \\
\hline Influenza and pneumonia & $90.8(89.7$ to 92.0$)$ & 20.0 (19.1 to 21.0$)$ & 11.1 (9.4 to 13.0$)$ \\
\hline Alzheimer's disease & $0.2(0.1$ to 0.2$)$ & 5.3 (4.9 to 5.8$)$ & $5.2(4.2$ to 6.5$)$ \\
\hline Accidents & 20.2 (19.6 to 20.8 ) & $17.7(16.8$ to 18.7$)$ & $16.0(13.9$ to 18.4$)$ \\
\hline Chronic lower respiratory diseases & $51.0(50.1$ to 51.9$)$ & 21.4 (20.5 to 22.4$)$ & 9.4 (7.8 to 11.2$)$ \\
\hline Japanese & Japan & & \\
\hline All cause & 799.1 (798.3 to 799.8$)$ & 613.8 (591.5 to 636.8$)$ & 600.2 (591.1 to 609.5$)$ \\
\hline Cancer & 268.2 (267.8 to 268.6 ) & $185.6(173.6$ to 198.3$)$ & 159.1 (154.4 to 164.0$)$ \\
\hline Heart disease & 115.0 (114.8 to 115.3$)$ & $142.9(132.1$ to 154.4$)$ & $157.8(153.3$ to 162.5$)$ \\
\hline Cerebrovascular diseases & $80.2(80.0$ to 80.4$)$ & 43.1 (37.3 to 49.7$)$ & 39.4 (37.3 to 41.8$)$ \\
\hline Communicable and nutritional conditions & 90.1 (89.8 to 90.3$)$ & 32.9 (27.7 to 38.8$)$ & 30.6 (28.7 to 32.7$)$ \\
\hline Influenza and pneumonia & 71.1 (70.9 to 71.3$)$ & $21.2(17.0$ to 26.3$)$ & 18.8 (17.4 to 20.3$)$ \\
\hline Alzheimer's disease & $1.3(1.2$ to 1.3$)$ & $9.7(6.9$ to 13.4$)$ & $9.7(8.8$ to 10.7$)$ \\
\hline Accidents & 36.4 (36.2 to 36.6$)$ & 33.2 (28.5 to 38.6$)$ & 26.5 (24.2 to 29.1$)$ \\
\hline Chronic lower respiratory diseases & $16.0(15.9$ to 16.1$)$ & $15.4(11.8$ to 19.8$)$ & $18.3(16.9$ to 20.0$)$ \\
\hline
\end{tabular}

central illustration (figure 1) pictorially demonstrates mortality differences among subgroup populations (ethnicity, nativity status, sex) by top causes of death.

Finally, we examined mortality trend data from 2003 to 2011 in the USA, Hong Kong and Japan for Chinese and Japanese populations, as shown in figure 2. Notably, Chinese trends indicate that mortality rates steadily decreased in Hong Kong since 2003 (annual per cent change (APC) for F: $-10.5, \mathrm{p}<0.05$; M: $-6.0, \mathrm{p}<0.05$; see online supplementary table S1). Japanese all-cause rates have decreased in Japan over the study period as well (F: $-4.2, \mathrm{p}<0.05$; $\mathrm{M}$ : $-10.7, \mathrm{p}<0.05$; see online supplementary table S2). Mortality rates by year with 95\% CIs and APC estimates with $\mathrm{p}$ values (see online supplementary tables S1 and S2) and cause-specific mortality rates (see online supplementary figures S1 and S2) were presented as online supplementary data. Cancer, heart disease and cerebrovascular diseases decreased in 
Cause Specific Mortality

(combined 9 years)
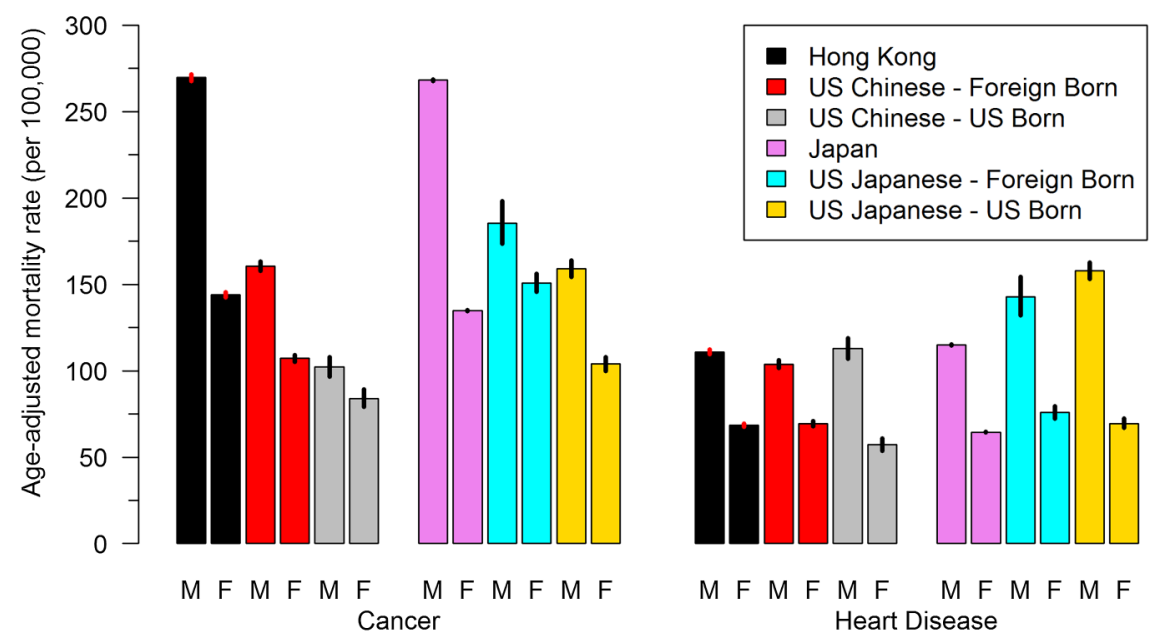

\section{Cause Specific Mortality (combined 9 years)}
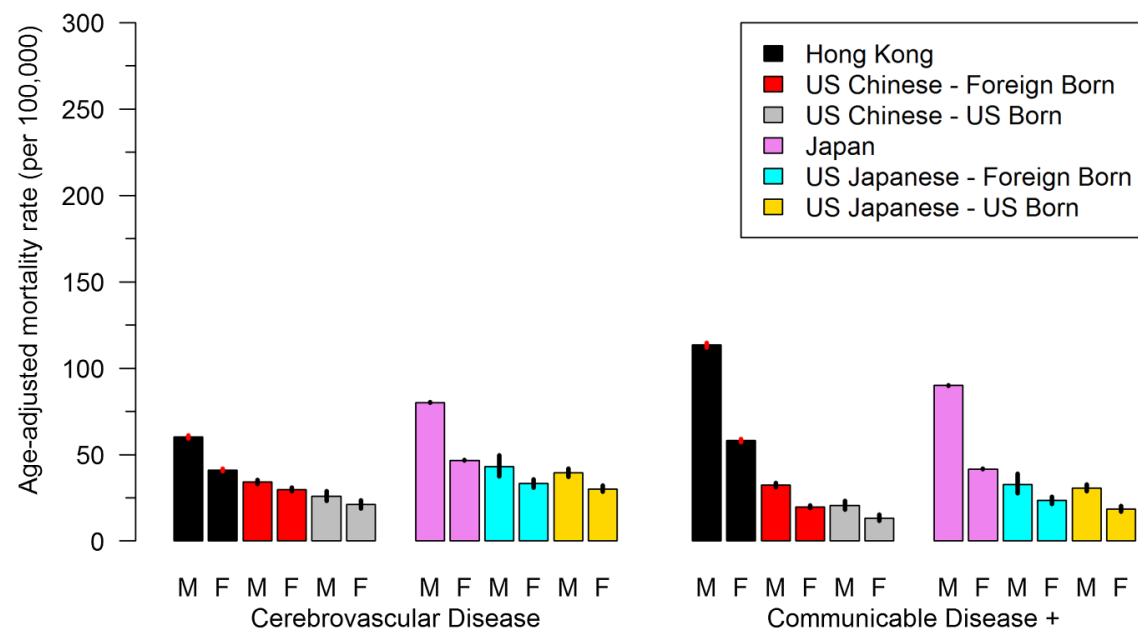

Figure 1 Central illustration: age-adjusted mortality rates for Chinese and Japanese populations by top causes of death (cancer, heart disease, cerebrovascular disease and communicable diseases); combined study years (2003-2011).

Hong Kong for females and males (see online supplementary figure S1). The same is true for Japan, in addition to communicable diseases (see online supplementary figure S2). Conversely, cancer mortality increased by $2 \%$ for Chinese and $4 \%$ for Japanese foreign-born females, and 9\% for Japanese foreign-born males (see online supplementary tables S1 and S2).

\section{DISCUSSION}

Our study aimed to disaggregate national mortality data by Asian-American subgroup (Chinese and Japanese), nativity status (foreign-born vs US-born), sex and country of origin (Hong Kong and Japan) to capture cause of death heterogeneity between groups. Incorporating country of origin data also provides a holistic overview of how certain populations may fare on immigration in the USA. The study also aimed to report mortality trends to understand where improvements may or may not be occurring for each population. We showed that US-born Asians have better mortality outcomes than foreign-born Asians, an opposite effect to what has been observed among Hispanic/Latinos in the USA. ${ }^{24}$ Furthermore, our study showed better mortality outcomes and higher educational attainment for foreign-born counterparts compared with populations in native countries, suggestive of selective migration. We explored causespecific mortality to provide insight into where most of these mortality gains were made, largely from improvements in cancer mortality in the US-born group when compared with decedents in countries of origin.

Population-level and infrastructural differences that support or undermine health may contribute to 
Chinese - Male

All Cause

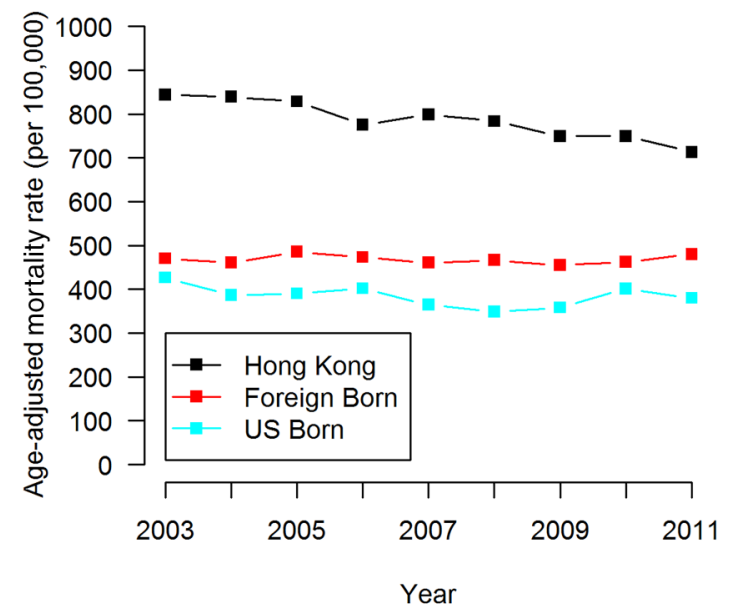

Japanese - Male

All Cause

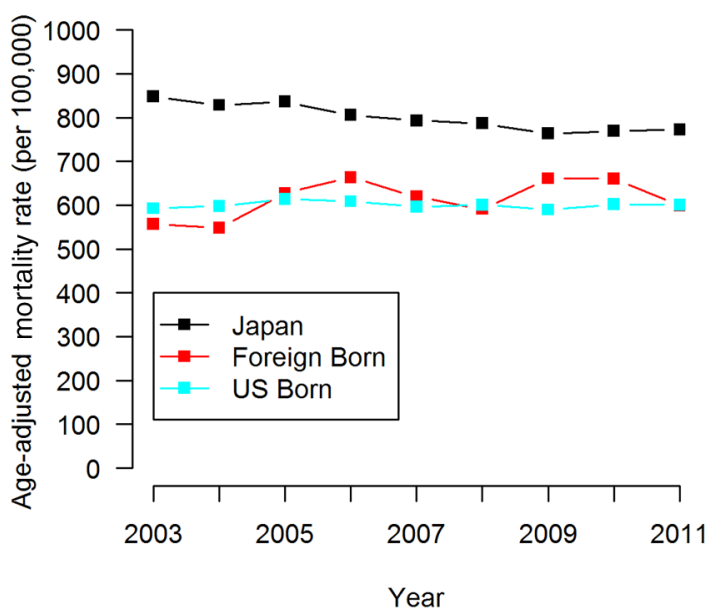

Chinese - Female

All Cause

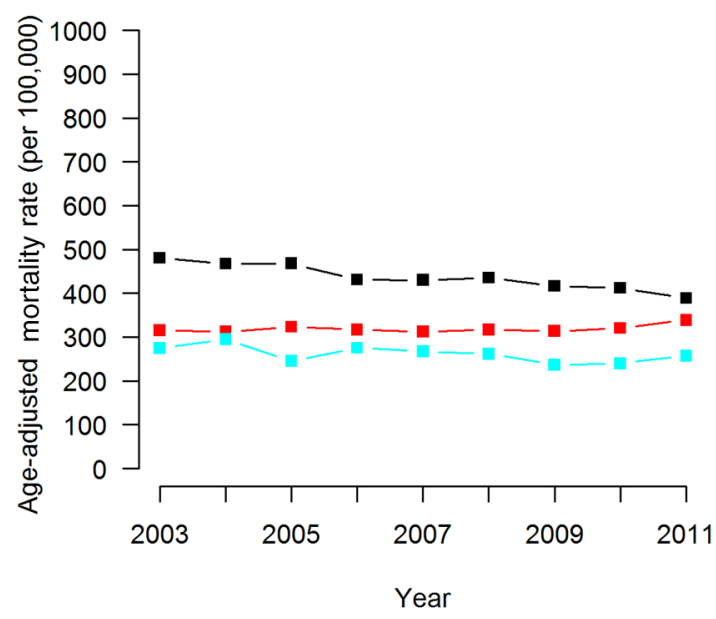

Japanese - Female

All Cause

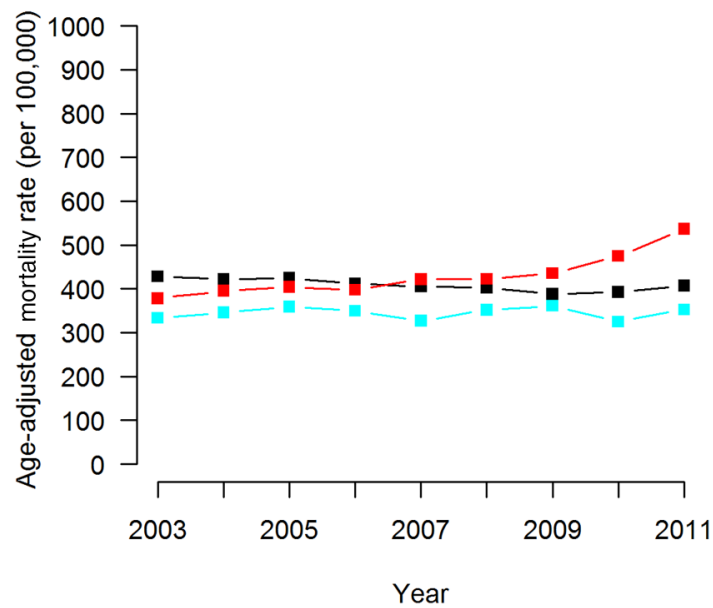

Figure 2 Year by year all cause age-adjusted mortality rates plotted from 2003 to 2011 for Chinese and Japanese populations by sex.

observed mortality patterns. For example, the mortality advantage among Asians in the USA (foreign-born and US-born) compared with Hong Kong and Japan is likely explained by decreased exposures to communicable diseases in these countries. ${ }^{25}$ Selective migration may also help explain the observed attenuation in foreign-born mortality rates and increased education attainment levels compared with developed Asia counterparts. A 'healthy' migrant does not exclusively indicate an advantage over US-born and/or majority populations, but rather how they fare in comparison to sending countries as well. Mexican migrants to the USA have shown not to be a selected group of their country of origin (ie, Mexico), unlike migrants from other distant countries such as in Asia. ${ }^{26}$

The mortality advantage for US-born decedents compared with foreign-born counterparts may be largely attributed to inadequate access to healthcare and health insurance for immigrant populations according to the
Migration Policy Institute. ${ }^{27}$ Their analyses using Census data show that immigrants were more than three times as likely to be uninsured (44\%) as native-born citizens (13\%). According to 2008-2010 ACS data, one study found that certain Asian-American subgroups, such as Chinese and Japanese, were on the lower end of the uninsured population, with Japanese at $7 \%$ and Chinese at $14 \%$, compared with the national average of $16 \% .^{28}$ This same study showed that Asians with larger percentages of native-born populations were less likely to be uninsured.

Our study has also shown that different causes of death were more important for each subgroup. Increased cancer mortality rates in foreign-born groups compared with US-born are likely caused by higher exposure levels to communicable/infectious diseases in countries of origin ${ }^{25}$ and lack of access to preventive screenings for early detection due to higher uninsured rates among foreign-born populations. ${ }^{28}$ Liver cancer 
has shown to be more important for Chinese immigrants, which likely reflects the high rates of chronic hepatitis B virus in certain Asian countries, such as China and Vietnam. ${ }^{29}$ Other studies have demonstrated that stomach cancer mortality rates are higher for foreign-born Japanese, reflecting the influence of rates of Helicobacter pylori infection and traditional dietary intake of pickled and salted foods. ${ }^{30} 31$

Increased heart disease mortality rates among Japanese men, and an overall greater proportion of heart disease deaths among all US-born subgroups, may be attributed to acculturation and increased CVD risk factors as illustrated by the landmark Ni-Hon-San study. ${ }^{32} 33$ The Honolulu Heart Program (HPP) evaluated CVD among Japanese men living in Honolulu within the Ni-Hon-San cohort and showed that risk factor levels of those men had risen to levels comparable to non-Hispanic whites (NHWs). ${ }^{34}$ However, stroke and coronary heart disease had remained lower than for NHWs. The children of HHP study participants were also followed, and investigators found that body mass index and diabetes prevalence were substantially higher in children compared with their fathers, however total cholesterol was lower in children. ${ }^{35}$ These observations suggest that acculturation such as adopted dietary and lifestyle behaviours similar to majority populations in the USA contribute to changes in CVD risk factors (ie, increased blood pressure and decreased smoking and alcohol intake) and, subsequently, increased heart disease and decreased stroke mortality, respectively, as also shown in our findings.

Previous studies of foreign-born aggregated Asian-Americans have shown lower rates of all-cause mortality compared with their US-born counterparts, ${ }^{36}$ consistent with health outcomes demonstrated among Hispanic/Latino immigrants in the USA. ${ }^{37}$ As we begin to disentangle ambiguities in mortality outcomes by Asian subgroup, we show that such patterns are not equally reflected among all groups. A similar study disaggregating Asian-Americans by foreign-born and US-born decedents showed that while Asian Indian, Korean and Vietnamese foreign-born populations had lower all-cause mortality rates and a higher life expectancy than US-born counterparts, the opposite was true for Chinese, Filipino and Japanese immigrants. ${ }^{30}$ More research must be carried out to investigate the forces that lead to large variations between immigrant groups in the USA, and how the health of immigrant children may differentiate from their own (ie, generational differences). One study speculated that health advantages over other ethnicities might accrue with longer histories of settlement in the USA like with Japanese-Americans and Chinese-Americans. ${ }^{38}$ Such analyses may provide important clues as to what degree socioenvironmental contexts may play over genetic risk factors in immigrant health.

Limitations include the use of the US mortality death records, which may contain errors in the documented cause of death and racial/ethnic misclassification leading to under-represented or over-represented causespecific death rates. ${ }^{39}$ We acknowledge that the sample for Japanese foreign-born men ( 2200 decedents, or $22 \%$ of Japanese foreign-born) is small, which may limit our interpretation for direct comparisons with other subgroups. The gender imbalance in Japanese migration to the USA has been previously explained by the influx of 'war brides' from 1952 to 1960, whereby Japanese women entered the USA as wives and fiancées of American military personnel. ${ }^{40}$ Additionally, foreignborn data do not indicate duration of residence, and does not differentiate between naturalised immigrants, permanent residents, non-immigrants (eg, temporary workers, students and visitors) and illegal immigrants, limiting our interpretations. ${ }^{10}$ Comparability of the USA and international mortality databases may be compromised due to differences in reporting and coding practices by country. To minimise this uncertainty, authors chose to emphasise causes for which we had reason to believe coding was similar (cardiovascular, cancer, communicable disease), and acknowledge that some causes, such as Alzheimer's disease, ${ }^{41}$ may vary substantially. Incomplete country comparison groups for the Chinese population (Hong Kong) as available in the WHO Mortality Database may limit our interpretations. However, this segmented Chinese population better controls for differences in level of economic development and access to medical technologies, etc. Population sizes are estimated rather than known, so the precision of age-standardised mortality rates may be less than expected and the CIs too narrow. Results are not generalisable to other Asian subgroups, and rates in Hong Kong are not generalisable to mainland China.

From a theoretical standpoint, it is important to consider that all-cause mortality rates among foreign-born groups may be underestimated by reverse migration causing 'statistical immortality'. This arises if immigrants leave the USA in old age and die in other countries without dropping appropriately from the US Census denominator. Reverse migration may be highly selective, with sicker immigrants more inclined to return to their country of origin if and when they cannot work, and for those with chronic (rather than sudden) causes of death. A recent study found selective reverse migration to be true among Mexican migrants in the USA, with higher probabilities of Mexican migrants in poor health to return home (and lower probabilities of return in improving health) ${ }^{42}$ Statistical immortality may differ by Asian subgroup, given possible differences in ease of return migration. For instance, it may be easier for US citizens to return migrate to Japan rather than China, given the more favourable visa and citizenship requirements. ${ }^{43} 44$ There are also more social protection systems for the elderly in Japan, ${ }^{45}{ }^{46}$ compared with China. ${ }^{47}$ The exact numbers of return migrants from the USA to these respective countries is unknown.

Traditionally, mortality analyses are a valid indicator of a population's health status, yet our findings warrant 
further investigation on the socioeconomic indicators impacting mortality outcomes, other health risk factors and healthcare usage differences between foreign-born and US-born counterparts. In effort to improve current targeted prevention strategies for racial/ethnic minorities, our data suggest that heart disease risk factor modification is more important for US-born Chinese and Japanese (similar to majority population) than foreignborn counterparts. Cancer screenings may be more important for foreign-born Chinese and Japanese, such as screening for gastric cancer and liver cancer (infection-induced cancers).

A substantial knowledge gap exists on this topic largely because comparing mortality rates across countries is complex given the differences in disease definitions, racial/ethnic classifications, numbers of years for which data are available, and methods of standardisation. Accounting for these limitations, our analyses provide an empirical basis for understanding health disparities among two diverse Asian immigrants in the USA, compared with developed Asia counterparts. The main findings of our study highlight the importance that not only race/ethnicity plays, but also nativity status, in unveiling mortality disparities for minority populations in the USA.

\section{Author affiliations}

${ }^{1}$ Division of General Medical Disciplines, Stanford University School of Medicine, Stanford, California, USA

${ }^{2}$ Shorenstein Asia-Pacific Research Center, Stanford University, Stanford, California, USA

${ }^{3}$ Quantitative Sciences Unit, Stanford University School of Medicine, Stanford, California, USA

${ }^{4}$ Population Health Sciences Division, Stanford University School of Medicine, Stanford, California, USA

${ }^{5}$ Center for Innovation in Global Health, Stanford University, Stanford, California, USA

Acknowledgements The authors would like to thank Dr Haley Hedlin for her oversight and expertise of the analytic planning, and Beinan Zhao for data cleaning and providing preliminary analyses, on an earlier version of this study.

Contributors KGH and KE designed the analytic plan and formulated research questions/hypotheses. KIK and DB data cleaned, analysed the data and generated figures. KE, MB, MRC and LPP provided content expertise and critical overview of the various drafts. MRC and LPP are study co-principal investigators. All authors were involved in interpreting findings and revising the first draft, which was written by KGH. All authors approved the final draft of the manuscript.

Funding This work was supported by the National Institute for Minority Health and Health Disparities at the National Institutes of Health (R01 MD 007012).

Competing interests None declared.

Provenance and peer review Not commissioned; externally peer reviewed.

Data sharing statement All data underlying the authors' findings in this study are freely available in public repositories, regulated by the National Center for Health Statistics (NCHS) and the WHO. The authors have obtained individual county-level characteristic data from NCHS for the analyses, thus its public use is restricted. If interested in acquiring these data, please visit the following link for more information: http://www.cdc.gov/nchs/data_access/ data_linkage/mortality/data_files_data_dictionaries.htm.
Open Access This is an Open Access article distributed in accordance with the Creative Commons Attribution Non Commercial (CC BY-NC 4.0) license, which permits others to distribute, remix, adapt, build upon this work noncommercially, and license their derivative works on different terms, provided the original work is properly cited and the use is non-commercial. See: http:// creativecommons.org/licenses/by-nc/4.0/

\section{REFERENCES}

1. The World Health Organization. The top 10 causes of death. Geneva, Switzerland, 2014 (cited 12 August 2015). http://www.who. int/mediacentre/factsheets/fs310/en/

2. IOM International Organization for Migration. World Migration Report 2010-the future of immigration: building capacities for change. Geneva, Switzerland, 2011. http://publications.iom.int/bookstore/free/ WMR_2010_ENGLISH.pdf

3. Kreps GL, Sparks L. Meeting the health literacy needs of immigrant populations. Patient Educ Couns 2008;71:328-32.

4. Saposnik G, Redelmeier DA, Lu H, et al. Myocardial infarction associated with recency of immigration to Ontario. QJM 2010;103:253-8.

5. Chiu M, Austin PC, Manuel DG, et al. Cardiovascular risk factor profiles of recent immigrants vs long-term residents of Ontario: a multi-ethnic study. Can J Cardiol 2012;28:20-6.

6. Okrainec K, Bell CM, Hollands S, et al. Risk of cardiovascular events and mortality among a population-based cohort of immigrants and long-term residents with diabetes: are all immigrants healthier and if so, for how long? Am Heart J 2015;170:123-32.

7. Albin B, Hjelm K, Elmståhl S. Comparison of stroke mortality in Finnish-born migrants living in Sweden 1970-1999 and in Swedish-born individuals. J Immigr Minor Health 2014;16:18-23.

8. Bennet L, Agardh CD, Lindblad U. Cardiovascular disease in relation to diabetes status in immigrants from the Middle East compared to native Swedes: a cross-sectional study. BMC Public Health 2013;13:1133.

9. Zallman L, Himmelstein DH, Woolhandler S, et al. Undiagnosed and uncontrolled hypertension and hyperlipidemia among immigrants in the US. J Immigr Minor Health 2013;15:858-65.

10. Singh GK, Siahpush M. All-cause and cause-specific mortality of immigrants and native born in the United States. Am J Public Health 2001;91:392-9.

11. Bostean G. Does selective migration explain the hispanic paradox? A comparative analysis of Mexicans in the US. and Mexico. J Immigr Minor Health 2013;15:624-35.

12. United Nations Department of Economic and Social Fairs. World Population Prospects: The 2012 Revision. 2012 (cited 12 August 2015). http://populationpyramid.net/world/2015/

13. US. Census Bureau. U.S. Census Bureau Projections Show a Slower Growing, Older, More Diverse Nation a Half Century from Now. 2012 (cited 12 August 2015). http://www.census.gov/ newsroom/releases/archives/population/cb12-243.html

14. Hastings KG, Jose PO, Kapphahn KI, et al. Leading causes of death among Asian American subgroups (2003-2011). PLoS ONE 2015;10:e0124341.

15. Jose PO, Frank AT, Kapphahn Kl, et al. Cardiovascular disease mortality in Asian Americans. J Am Coll Cardiol 2014;64:2486-94.

16. Frank $A T$, Zhao $B$, Jose PO, et al. Racial/ethnic differences in dyslipidemia patterns. Circulation 2014;129:570-9.

17. Gomez SL, Clarke CA, Shema SJ, et al. Disparities in breast cancer survival among Asian women by ethnicity and immigrant status: a population-based study. Am J Public Health 2010;100:861-9.

18. U.S. Census Bureau. Asian Alone by Selected Groups American Community Survey 1-Year Estimates 2011.

19. Palaniappan LP, Araneta MR, Assimes TL, et al. Call to action: cardiovascular disease in Asian Americans: a science advisory from the American Heart Association. Circulation 2010;122:1242-52.

20. Zhou M, Wang H, Zhu J, et al. Cause-specific mortality for 240 causes in China during 1990-2013: a systematic subnational analysis for the Global Burden of Disease Study 2013. Lancet 2016;387:251-72.

21. Becker R, Silvi J, Ma Fat D, et al. A method for deriving leading causes of death. Bull World Health Organ 2006;84:297-304.

22. Ahmad OB PC, Lopez AD, Murray CJL, et al. Age standardization of rates: a new WHO standard. Geneva, Switzerland: World Health Organization, 2001 (cited 12 August 2015). http://www.who.int/ healthinfo/paper31.pdf

23. United States Census Bureau. American Community Survey 2010. 2013 (cited 12 August 2015). http://www.census.gov/prod/2012pubs/ acs-19.pdf

24. Hamilton TG. The healthy immigrant (migrant) effect: In search of a better native-born comparison group. Soc Sci Res 2015;54:353-65. 
25. Gupta I, Guin P. Communicable diseases in the South-East Asia Region of the World Health Organization: towards a more effective response. 2010 (cited 6 June 2016). http://www.who.int/bulletin/ volumes/88/3/09-065540/en/

26. Kaestner R, Malamud O. Self-selection and international migration: new evidence from Mexico. Rev Econ Stat 2014;96:78-91.

27. Ku L. Why Immigrants Lack Adequate Access to Health Care and Health Insurance Washington DC. 2006. http://www.migrationpolicy. org/article/why-immigrants-lack-adequate-access-health-care-andhealth-insurance

28. Huang A. Disparities in health insurance coverage among Asian Americans. Asian Am Policy Rev 2012;23:41.

29. Mast EE, Margolis HS, Fiore AE, et al., Advisory Committee on Immunization Practices (ACIP). A comprehensive immunization strategy to eliminate transmission of hepatitis $B$ virus infection in the United States: recommendations of the Advisory Committee on Immunization Practices (ACIP) part 1: immunization of infants, children, and adolescents. MMWR Recomm Rep 2005;54:1-31.

30. Singh GK, Miller BA. Health, life expectancy, and mortality patterns among immigrant populations in the United States. Can J Public Health 2004:95:114-21.

31. Kamineni A, Williams MA, Schwartz SM, et al. The incidence of gastric carcinoma in Asian migrants to the United States and their descendants. Cancer Causes Control 1999;10:77-83.

32. Marmot MG, Syme SL, Kagan A, et al. Epidemiologic studies of coronary heart disease and stroke in Japanese men living in Japan, Hawaii and California: prevalence of coronary and hypertensive heart disease and associated risk factors. Am J Epidemiol 1975;102:514-25.

33. Worth RM, Kato H, Rhoads GG, et al. Epidemiologic studies of coronary heart disease and stroke in Japanese men living in Japan, Hawaii and California: mortality. Am J Epidemiol 1975;102:481-90.

34. Stemmermann GN, Steer A, Rhoads GG, et al. A comparative pathology study of myocardial lesions and atherosclerosis in Japanese men living in Hiroshima, Japan and Honolulu, Hawaii. Lab Invest 1976;34:592-600.

35. Narayan KMV, Aviles-Santa L, Oza-Frank R, et al. Report of a National Heart, Lung, and Blood Institute Workshop: heterogeneity in
Cardiometabolic Risk in Asian Americans in the U.S.: opportunities for Research. J Am Coll Cardiol 2010;55:966-73.

36. Singh GK, Hiatt RA. Trends and disparities in socioeconomic and behavioural characteristics, life expectancy, and cause-specific mortality of native-born and foreign-born populations in the United States, 1979-2003. Int J Epidemiol 2006;35:903-19.

37. McCarthy M. CDC report confirms "Hispanic paradox". BM 2015;350:h2467.

38. Frisbie WP, Cho Y, Hummer RA. Immigration and the health of Asian and Pacific Islander adults in the United States. Am $J$ Epidemiol 2001;153:372-80.

39. Frisbie WP, Cho Y, Hummer RA. Immigration and the health of Asian and Pacific Islander adults in the United States. American Journal of Epidemiology 2001;153:372-80.

40. Min PG. Asian Americans. Contemporary trends and issues. Sage Focus Editions, 2005

41. Trovato F, Lalu NM. Contribution of cause-specific mortality to changing sex differences in life expectancy: seven nations case study. Soc Biol 1998;45:1-20.

42. Acciai F, Noah AJ, Firebaugh G. Pinpointing the sources of the Asian mortality advantage in the USA. J Epidemiol Community Health 2015;69:1006-11.

43. The Law Library of Congress. Citizen pathways and border protection. Japan. 2015 (cited 5 June 2016). http://www.loc.gov/law/ help/citizenship-pathways/japan.php-Citizenship

44. The Law Library of Congress. Citizenship pathways and border protection. China, 2015 (cited 5 June 2016). http://www.loc.gov/law/ help/citizenship-pathways/china.php

45. Social Security Office of Retirement and Disability Policy. Social Security Programs Throughout the World: Asia and the Pacific 2010. 2010 (cited 5 June2016). https://http://www.ssa.gov/policy/ docs/progdesc/ssptw/2010-2011/asia/japan.html

46. Reich MR, Shibuya K. The future of Japan's health systemsustaining good health with equity at low cost. $N$ Engl J Med 2015;373:1793-7.

47. The Economist. Pensions: Social security with Chinese characteristics. 2012 ([cited 5 June 2016). http://www.economist. com/node/21560259 